\title{
Р. Р. ЯРУЛЛИН,
}

\section{доктор экономических наук, профессор, академик Российской академии естествознания}

Уфимский филиал Финансового университета при Правительстве Российской Федераџии, 2. Уфа, Россия

\section{АРЕНДНАЯ ПЛАТА ЗА ИСПОЛЬЗОВАНИЕ НЕЖИЛОГО ФОНДА КАЗНЫ ГОРОДСКОГО ОКРУГА И ФАКТОРЫ ЕЕ РОСТА}

Цель: разработка теоретических основ формирования арендной платы за аренду нежилого фонда, составляющего казну городского округа г. Уфы и выявление возможностей роста доходов бюджета от его использования.

Методы: абстрактно-логический, диалектический, сравнительный, системный и структурный, экономический, анализ и синтез.

Результаты: раскрыто содержание арендной платы за использование нежилого фонда, составляющего казну городского округа как денежного платежа, носящего возмездный и эквивалентный характер, за пользование казной муниципального образования;

обоснована необходимость повышения бюджетной эффективности аренды городских объектов нежилого фонда, заключающаяся в целевом использовании арендных платежей на содержание, инвестиции в ремонт и строительство нежилых объектов, наличие средств для их финансирования, а также отсутствие роста арендной платы выше экономически оправданного порога;

проведен анализ факторов поступлений в бюджет арендной платы, влияющих на бюджетную эффективность аренды объектов нежилого фонда г. Уфы;

выявлен ряд проблемных вопросов, носящих системный характер: снижение количества договоров аренды; сокращение арендуемых площадей; чрезмерный объем льгот по арендной плате; имеющаяся задолженность арендаторов по арендной плате; недостаточное совершенство работы информационной системы управления;

предложены пути повышения эффективности и доходности бюджета от сдачи в аренду нежилого фонда, состоящие в переводе нежилых зданий и помещений, находящихся в хозяйственном ведении, оперативном управлении или неиспользуемых (неоформленных), в режим арендования с установлением посильной для арендаторов арендной платы; расширение количества площадей, арендная плата за использование которых устанавливается посредством проведения торгов; сокращение льгот коммерческим организациям по оплате аренды помещений; обеспечение полного и своевременного внесения в бюджет задолженности с арендаторов; ускорение работы по формированию автоматизированной системы массовой оценки недвижимости, позволяющей автоматизировать прогноз поступлений в бюджет от аренды нежилого фонда.

Научная новизна: обоснована необходимость повышения бюджетной эффективности аренды городских объектов нежилого фонда, сформулирована дефиниция арендной платы за использование нежилого фонда казны городского округа, и выявлены факторы ее роста.

Практическая значимость: положения и выводы статьи могут быть использованы в процессе управления бюджетной эффективностью аренды объектов нежилого фонда, а также в научной и педагогической деятельности.

Ключевые слова: аренда; нежилой фонд; имущество; казна; арендная плата; городской бюджет; бюджетная эффективность; информационная система.

\section{Введение}

На современном этапе расширения сферы рыночных отношений важное место в управлении городским хозяйством занимает нежилой фонд, в его использовании традиционно ведущей формой выступает аренда. В условиях социально-экономического кризиса и постоянного дефицита бюджетных ресурсов перед муниципальными образованиями встали вопросы бюджетной эффективности аренды объектов нежилого фонда. Плата за данные фонды, вследствие наличия в РФ огромного массива городского имущества, может служить значительным источником поступления муниципального бюджета [1, с. 171]. Однако она составляет незначительную долю в источниках городской казны, курируемых Управлением муниципальной собственности. Ее доля в бюджете городских округов РФ по состоянию на 01.06.2015 составила всего лишь 0,64 \% (4 045 743,3 тыс. руб.), а в бюджете городского 
округа г. Уфы - $1,75 \%{ }^{1}$. Причем в г. Уфе поступления в общей структуре доходов от деятельности управления составляют одну треть, т. е. 27,3\%.

Вопросы бюджетной эффективности аренды городских объектов нежилого фонда в современных условиях явились предметом исследования многих отечественных ученых. Существенный вклад в повышение эффективности управления арендой городской недвижимости внесли такие ученые и практики, как В. Н. Лексин, Н. Н. Ноздрина, И. А. Рахман, В. И. Ресин, В. Г. Ростанец, И. М. Рукина, О. М. Толкачев, А. Н. Швецов и др. [2-9]. В немногочисленных разработках исследователей, среди которых Л. П. Павлова, В. М. Пушкарева, В. М. Родионова и другие ученые [10-12], рассматриваются отдельные вопросы формирования доходов бюджета за счет использования различных объектов государственной собственности. Однако уровень теоретической разработанности данной проблемы является недостаточным и не отвечает потребностям практики, не получили достаточной проработки вопросы, связанные с финансовыми последствиями реализации мероприятий в области управления собственностью для бюджета, изучением факторов снижения дохода бюджета от использования муниципальной собственности. Исходя из этого, вышеизложенные проблемы приобретают особую актуальность.

\section{Результаты исследования}

В Уфе функции арендодателя при сдаче в аренду имущества выполняет Управление муниципальной собственности Администрации городского округа город Уфа Республики Башкортостан. Согласно порядку осуществления администрацией и ее функциональными органами бюджетных полномочий главных администраторов доходов бюджетов в 2015 г. на управление возложены функции главного администратора доходов по двадцать одному коду бюджетной классификации, в том числе по статье «доходы от сдачи в аренду имущества, составляющего казну городских округов (за исключением земельных участков)». Плановое задание по администрированию доходов от сдачи в аренду объектов муниципального нежилого фонда на 2015 год составляет 460 000,0 тыс. руб.

\footnotetext{
1 Отчет Федерального казначейства РФ об исполнении консолидированного бюджета субъекта Российской Федерации и бюджета территориального государственного внебюджетного фонда. URL: http://roskazna.ru/byudzhetov-subektov-rf-imestnykh-byudzhetov// (дата обращения: 10.08.2015).
}

Представляет интерес выяснение дефиниции платежа. Поскольку он представляет собой комплексную составляющую, рассмотрим вначале понятие «казна», которое, к сожалению, практически ни один из нормативных документов, включая и Бюджетный кодекс РФ (далее - БК РФ), не раскрывает. Его правовой аспект, закрепленный на общефедеральном уровне еще в 1994 г., изложен лишь в положении п. 3 ст. 215 «Право муниципальной собственности» Гражданского кодекса РФ (далее - ГК РФ), согласно которому муниципальная казна составляет средства бюджета и иное имущество, не закрепленное за муниципальными организациями ${ }^{2}$. В статье под муниципальной казной понимаются объекты муниципального нежилого фонда.

Арендная плата за нежилые помещения рассматривается в системе доходов бюджетной классификации как доходы от сдачи в аренду имущества. На наш взгляд, в названии платежа термин арендуемого объекта целесообразно сузить, поскольку в состав имущества помимо нежилого фонда входят земельные участки, участки недр и все, что прочно связано с землей ${ }^{3}$. На практике имущество органов местного самоуправления для использования в различных целях, признанное в установленном порядке нежилыми помещениями, передается в аренду (субаренду) только в форме нежилого фонда, который включает комплексы или отдельно стоящие здания, строения и сооружения; встроенно-пристроенные нежилые помещения в объектах жилищного фонда; здания, строения и сооружения, отнесенные к памятникам истории, архитектуры и культуры ${ }^{4}$.

Упоминание в названии платежа термина «доходы» также некорректно, поскольку в его состав входит лишь один доход - арендная плата.

Исходя из этого, целесообразно данный источник бюджета называть в системе доходов бюджетной классификации арендной платой за использование нежилого фонда, составляющего казну городского

2 Гражданский кодекс РФ: Части первая - четвертая: [Принят Госдумой 21 октября 1994 года, с изменениями и дополнениями по состоянию на 13 июля 2015 г.] // Собрание законодательства РФ. 1994. № 22. Ст. 2457.

3 Там же.

4 Положение о порядке управления и распоряжения объектами муниципального нежилого фонда, находящимися в собственности городского округа город Уфа Республики Башкортостан: решение Совета городского округа город Уфа Республики Башкортостан от 19 марта 2009 № 14/8. URL: http:// base.consultant.ru/regbase/cgi/online.cgi?base=RLAW140; frame= 1;n=93673;req=doc (дата обращения: 10.08.2015). 
округа, и представить как денежный платеж, носящий возмездный и эквивалентный характер, за пользование казной муниципального образования [13, с. 86].

Выявление роли недвижимости казны муниципального образования в современной России и тенденций изменения ее вклада в формирование доходной базы бюджета показало, что при необходимости быстрого и значительного пополнения бюджетных средств городские органы власти часто прибегают к продаже данных объектов, считая приватизацию признанным способом повышения эффективности их использования. Однако доходы от продажи собственности не могут компенсировать отрицательный эффект, возникающий в случае непродуманной политики в области приватизации арендуемой недвижимости. Проведение таких операций часто имеет негативные последствия, так как, уменьшая базу сдаваемого в аренду имущества, муниципальные образования теряют возможность регулярных денежных поступлений от аренды, их воспроизводство и приумножение возможно лишь при проведении рациональной политики арендных отношений, сводимой к бюджетной эффективности: арендные платежи должны использоваться прежде всего для финансирования затрат на содержание, инвестиции в ремонт и строительство нежилых объектов, обеспечивающих и поддерживающих расширенное воспроизводство с постоянным повышением эксплуатационных качеств, наличие средств для их финансирования, а также отсутствие роста арендной платы выше экономически оправданного порога.

При анализе значимости поступлений в бюджет от муниципальной недвижимости обращает на себя внимание слабая проработка вопросов бюджетного федерализма, в основе которой лежит принцип «доходы, полученные на муниципальном уровне и закрепленные за территориальным образованием, не подлежат изъятию и используются на цели социальноэкономического развития территории». В российском законодательстве этот принцип проработан слабо. В действующем БК РФ допускается изъятие доходов местных бюджетов без согласия местной администрации в пользу региональных органов. Недостатки механизма бюджетного федерализма и несовершенство процедур управления муниципальной собственностью приводят к тому, что вклад поступлений от аренды недвижимости в России в формирование финансовой базы местного самоуправления пока незначителен.

В целях решения рассматриваемых вопросов разберем факторы, влияющие на бюджетную эффективность аренды объектов нежилого фонда г. Уфы [14].
Для этого вначале следует отметить, что в течение последних 5 лет наблюдалось превышение фактического поступления арендной платы над ее плановой величиной. За период с 2010 по 2013 г. плата за аренду нежилых помещений увеличилась в 1,1 раза с 586246 до 642 968,2 тыс. руб. В 2014 г. поступление уменьшилось и составило 547 575,5 тыс. руб., за первое полугодие 2015 г. - 219275,9 тыс. руб. Этому во многом способствовало следующее:

1. Расширение практики заключения договоров аренды на основе торгов (аукционов), при котором процесс передачи в аренду городских помещений стал носить публичный характер, а ставки арендной платы стали определяться в соответствии с законами рынка. Количество договоров, заключенных по результатам торгов, за рассматриваемый период увеличилось на 326 (с 59 до 385). Значительно возросла доля площадей, выставляемых на специализированные торги от общей арендованной площади, - на 24,8 \% (с 1,7 до 26,5). При этом если годовая арендная плата за 1 кв. м, сложившаяся по результатам торгов в 2011 г, составила 6167 руб., то в 2012 г. - 6593 руб., в 2013 г. 7320 руб., в 2014 г. - 6673 руб. Если же учитывать в целом действующие договоры аренды с рыночной платой, включая аукционы, то их количество составляет 925 общей площадью 141,7 тыс. кв. м, или $48,2 \%$, и обеспечивает более 70 \% от общей суммы поступлений по арендной плате. Данный фактор, в свою очередь, оказал влияние на увеличение доли поступлений по договорам аренды с торгов от общей суммы поступлений по действующим договорам аренды - с 6,8 до 39,9 \%, а в стоимостном выражении с 39864,7 тыс. руб. до 218 844,8 тыс. руб.

2. Внесение изменений в Положение о порядке управления и распоряжения объектами муниципального нежилого фонда путем включения в него методов расчета на основе рыночной стоимости объекта недвижимости, порядка сдачи арендатором части объекта нежилого фонда в субарендное пользование, а также введения коэффициента планируемого повышения платы за использование объекта с учетом уровня инфляции на потребительских рынках 5 .

5 Положение о порядке управления и распоряжения объектами муниципального нежилого фонда, находящимися в собственности городского округа город Уфа Республики Башкортостан: решение Совета городского округа город Уфа Республики Башкортостан от 19 марта 2009 № 14/8. URL: http:// base.consultant.ru/regbase/cgi/online.cgi?base $=$ RLAW140; frame $=$ 1;n=93673;req=doc (дата обращения: 10.08.2015). 
Индексация арендных ставок по договорам аренды проводилась в течение 2011-2013 гг, ее размер составлял 1,$9 ; 2,12$ и 2,35, соответственно.

3. Увеличение площадей, сдаваемых арендаторами в субарендное пользование. Решением совета размер платы арендатора, сдающего в субарендное пользование часть помещения общей площадью до двух квадратных метров, увеличивается на 10 \% применительно ко всей арендуемой площади. В случае сдачи в субаренду помещения общей площадью более двух квадратных метров размер платы увеличивается в два раза.

4. Перечисление арендаторами задолженности по арендной плате и пеней за предыдущие периоды. Их доля уменьшилась за рассматриваемый период с 11 до $8 \%$ от фактически поступившей в бюджет арендной платы, или в суммовом выражении с 64 408,7 тыс. руб. до 42 844,9 тыс. руб. В составе задолженности числится сумма долга прошлых лет, занимающая, однако, две трети ее размера (в 2014 году - 67 \%). Эта доля остается неизменной с 2010 г. Уменьшение величины задолженности объясняется результатом активизации управления претензионно-исковой работы. Ежегодно подготавливается и направляется около 300 претензий и исковых заявлений о наличии задолженности, оплачивается свыше одной десятой части суммы задолженности.

Следующая группа факторов негативно сказывалась на поступлении неналогового дохода в городской бюджет:

1. В соответствии с приказом Минфина РФ от 21.12.2012 № 171н «Об утверждении Указаний о порядке применения бюджетной классификации Российской Федерации на 2013 год и плановый период 2014 и 2015 годов» в 2013 г. код бюджетной классификации «доходы от сдачи в аренду имущества, находящегося в оперативном управлении органов управления городских округов и созданных ими учреждений (за исключением имущества муниципальных бюджетных и автономных учреждений)» был разделен на два кода путем введения с 01.01.2013 нового кода «доходы от сдачи в аренду имущества, составляющего казну городских округов (за исключением земельных участков)». В результате платежи в городской бюджет от аренды муниципального имущества, переданного в оперативное управление муниципальным организациям, не поступали.

2. Снижение количества действующих договоров аренды объектов нежилого фонда (за анализируемый период - на 1 007, с 2576 до 1 569). Уменьшение про- слеживается по договорам с действующей Методикой расчета арендной платы при относительно низкой ее ставке в отличие от величины рыночной арендной платы, складывающейся при торгах.

3. Сокращение количества площадей, сдаваемых в аренду. Площади активов аренды за 5 лет сократились на 165,7 тыс. кв. м, а это примерно 262 170,5 тыс. руб., если считать от средней величины арендной платы за 1 кв. м (165,7 х 1582,2). К началу 2015 г. общая площадь нежилого фонда города, переданная в пользование, составила 2 506,4 тыс. кв. м, из них около $13 \%$ - в аренду различным организациям. Анализ данных свидетельствует о шестикратном превышении площадей, предоставляемых в хозяйственное ведение и оперативное управление, над площадями, сдаваемыми в аренду. Следовательно, фактически только десятая часть площадей, переданных в пользование, приносит стабильный доход в бюджет города.

4. Ликвидные помещения, ранее сдаваемые в аренду и приносившие доход в бюджет города, ежегодно уменьшаются, что объясняется отчуждением объектов муниципального нежилого фонда в порядке приватизации, в основном во исполнение положений Федерального закона об особенностях отчуждения недвижимого имущества ${ }^{6}$. С 2009 г. в связи с реализацией закона о льготной приватизации из арендного оборота выбыло 238,4 тыс. кв. м площадей, в т. ч. в 2015 г. - более 21 тыс. кв. м. Из оставшихся 1756 договоров текущей аренды 602 договора на общую площадь 110,1 тыс. кв. м заключены с субъектами малого бизнеса, которые подпадают под действие вышеуказанного закона и могут быть выкуплены по преимущественному праву выкупа.

5. Передача полномочий арендодателя муниципальным предприятиям. Это ставит определенную задачу перед Финансовым управлением совместно с отраслевыми его органами усилить контроль над доходами вышеуказанных учреждений от аренды в целях сокращения бюджетных дотаций для них.

6. Льготы по арендной плате, предоставляемые арендаторам на основании решения совета, использование при расчете арендной платы понижающих

\footnotetext{
6 Об особенностях отчуждения недвижимого имущества, находящегося в государственной собственности субъектов Российской Федерации или в муниципальной собственности и арендуемого субъектами малого и среднего предпринимательства, и о внесении изменений в отдельные законодательные акты Российской Федерации: Федеральный закон от 22 июля 2008 г. № 159-Ф3. URL: http://base.garant.ru/12161610/\#ixzz3hZ6HMDnb (дата обращения: 10.08.15).
} 
коэффициентов. В 2014 г. имущественная поддержка (выпадающие доходы) была применена в отношении 238 договоров аренды (13,5 \% от общего количества). Размер выпадающих доходов бюджета в связи с применением понижающего коэффициента использования по договорам с рыночной оценкой составил 14 945,5 тыс. руб., понижающего коэффициента стимулирования отдельных направлений деятельности - 5 296,2 тыс. руб., применения льгот по решениям совета - 44 117,8 тыс. руб. (15 договоров). Таким образом, от данных льгот и коэффициентов бюджет недополучил 64 359,5 тыс. руб. (12\% от плановой годовой арендной платы).

7. Освобождение с 2006 г. от арендной платы арендаторов на период проведения капитального ремонта в соответствии с решением совета № $3 / 10$ от 15.12.2005 «О порядке учета, управления и распоряжения объектами муниципального нежилого фонда г. Уфы». В текущем году были приняты решения об освобождении в отношении пяти арендаторов. Сумма инвестиционных (капитальных) вложений составила 10 801,3 тыс. руб., сумма выпадающих доходов 6 785,4 тыс. руб. Наибольшее количество данных арендаторов числилось в 2008, 2009 и 2014 гг. 18,16 и 17 , сумма вложений в ремонт - 36401 , 41311 и 37557 тыс. руб., соответственно. Сумма выпадающих поступлений в бюджет - 3 247, 6030 и 7 121,5 тыс. руб., соответственно.

8. Требует улучшения информационное обеспечение системы органов управления. Управление использует автоматизированную информационную систему ведения реестра имущества города «Имущество», реализующую возможности ведения реестра имущества, учета, анализа и контроля поступления средств по договорам аренды, их исполнения. Однако действующая система в полной мере не учитывает тенденции и конъюнктуру рынка недвижимости и обеспеченность населения бытовыми и социальными услугами, что предполагает применение методов анализа рынка недвижимости и услуг, используемых при оценке других форм собственности, и анализа обеспеченности жителей услугами социального значения. Все это определяет актуальность и обуславливает необходимость внедрения новых информационных технологий, заключающихся в использовании автоматизированной системы массовой оценки объектов недвижимости на основе компьютерных моделей ее рынка [15], которая позволяет автоматизировать расчет рыночной цены аренды недвижимости и прогноз поступлений в бюджет арендной платы.

\section{Выводы}

Приведенные данные и анализ формирования поступлений в бюджет от аренды помещений, находящихся в имущественной казне г. Уфы, выявили ряд проблем, носящих системный характер: снижение количества договоров аренды; сокращение арендуемых площадей; чрезмерный объем льгот по арендной плате; имеющуюся задолженность арендаторов по арендной плате; недостаточное совершенство работы информационной системы управления.

Решение по устранению выявленных проблем эффективности и доходности бюджета города от сдачи в аренду нежилого фонда:

- дальнейший перевод нежилого фонда, находящегося в хозяйственном ведении и оперативном управлении, в режим арендования с установлением посильной для арендаторов арендной платы;

- вовлечение в арендный оборот свободных, неиспользуемых, неоформленных нежилых зданий и помещений;

- расширение количества площадей, арендная плата за использование которых устанавливается посредством проведения торгов;

- осуществление мероприятий по реновации нежилых помещений, непригодных к использованию, для пополнения арендного фонда;

- сокращение льгот по оплате аренды нежилых помещений городской собственности, предоставляемых коммерческим организациям. Мониторинг состава и условий предоставления недвижимости в аренду на льготных условиях с целью выявления оправданных и устранения избыточных;

- принятие оперативных мер по взысканию задолженности с арендаторов и обеспечению полного их внесения в бюджет;

- совершенствование методической работы, основанной на определении размера арендной платы с использованием корректирующих коэффициентов, позволяющих значительно увеличить арендные платежи в масштабах муниципального образования;

- совершенствование работы информационных систем управления, заключающейся в формировании автоматизированной системы массовой оценки недвижимости на основе компьютерных моделей ее рынка, позволяющей автоматизировать прогноз поступлений в бюджет от аренды нежилого фонда;

- разработка и принятие целевой программы повышения бюджетной эффективности аренды объектов нежилого фонда г. Уфы на 2016-2020 гг. 


\section{Список литературы}

1. Яруллин Р. Р. Доходы бюджета: учеб. пособие. Уфа: ФГОУ ВПО БГАУ, 2005. 224 с.

2. Лексин В. Н. Города власти: административные центры России // Мир России: Социология, этнология. 2009. № 1. C. 3-33.

3. Ноздрина Н. Н., Стерник Г. М. Рынок жилья в городах России до и после августовского кризиса 1998 года // Проблемы прогнозирования. 2000. № 1. С. 120-141.

4. Рахман И. А. Развитие рынка недвижимости в России: теория, проблемы, практика. М.: Экономика, 2000. 294 с.

5. Ресин В. И. Управление развитием крупного города. Опыт системного исследования. М.: Голос, 1996. 336 с.

6. Ростанец В. Г., Топилин А. В. Перспективы межрегиональных интеграционных структур // Экономист. 2007. № 6. С. 81-87.

7. Рукина И. М., Анфимова А. Ю. Региональная экономика и управление: учеб. пособие. М.: Издательский дом Международного университета в Москве, 2014. 250 с.

8. Толкачев О. М. Эффективное управление имуществом прибыль городу // Городская собственность. 1998. № 4 (8).
9. Швецов А. Н. Государственная поддержка российских городов / Ин-т системного анализа Рос. акад. наук. 2-е изд., испр. М.: Эдиториал УРСС, 2002. 160 с.

10. Павлова Л. П., Бабич А. М. Государственные и муниципальные финансы: учебник для вузов. 2-е изд., перераб. и доп. М.: ЮНИТИ-ДАНА, 2012. 703 с.

11. Пушкарева В. М. История финансовой мысли и политики налогов: учеб. пособие. М.: Инфра-М, 1996. 192 с.

12. Финансы / В. М. Родионова, Ю. Я. Вавилова, Л. И. Гончаренко и др. М.: Финансы и статистика, 2011. $432 \mathrm{c}$.

13. Яруллин Р. Р. Концепция взимания государством доходов от имущества // Вестник Оренбургского государственного университета. 2008. № 85. С. 83-94.

14. Яруллин Р. Р. Доходы от сдачи в аренду объектов муниципального нежилого фонда и резервы их роста // Вестник Оренбургского государственного университета. 2015. № 8. С. 112-119.

15. Яруллин Р. Р. Оценка недвижимости: учеб. пособие. Уфа: Мир печати, 2008. 68 с.

В редакичию материал поступил 12.08 .15

(C) Яруллин Р. Р., 2015. Впервые опубликовано в журнале «Актуальные проблемы экономики и права» (http://apel.ieml.ru), 15.11.2015; лицензия Татарского образовательного центра «Таглимат». Статья находится в открытом доступе и распространяется в соответствии с лицензией Creative Commons Attribution License (http://creativecommons.org/licenses/by/2.0/), позволяющей неограниченно использовать, распространять и воспроизводить материал на любом носителе при условии, что оригинальная работа, впервые опубликованная в журнале «Актуальные проблемы экономики и права», процитирована с соблюдением правил цитирования. При цитировании должна быть включена полная библиографическая информация, ссылка на первоначальную публикацию на http://apel.ieml.ru, а также информация об авторском праве и лицензии.

\title{
Информация об авторе
}

Яруллин Рауль Рафаэлович, доктор экономических наук, профессор кафедры финансов и кредита, академик Российской академии естествознания, Уфимский филиал Финансового университета при Правительстве Российской Федерации

Адрес: 450015, г. Уфа, ул. Мустая Карима, 69/1, тел.: (347) 251-08-32

E-mail: jrr61@mail.ru

Как цитировать статью: Яруллин Р. Р. Арендная плата за использование нежилого фонда казны городского округа и факторы ее роста // Актуальные проблемы экономики и права. 2015. № 4. С. 181-187.

\author{
R. R. YARULLIN, \\ Doctor of Economics, Professor, Academician of the Russian Academy of Natural Sciences \\ Ufa branch of University for Finance at the Russian Government, Ufa, Russia
}

\section{RENTAL FEES FOR USING THE NON-RESIDENTIAL FUNDS OF THE MUNICIPAL FISC AND FACTORS OF ITS GROWTH}

Objective: to develop the theoretical bases of forming the rent fees for non-residential funds, which constitute the fisc of Ufa municipality, and to identify the opportunities of revenues increase from its use.

Methods: abstract-logical, dialectical, comparative, systematic and structural, economic analysis and synthesis.

Results: the content is disclosed of the rental fees of non-residential funds constituting the municipal fisc as a cash payment, of compensatory and equivalent character, for the use of the municipality fisc;

the necessity is grounded of increasing the budget effectiveness of the municipal non-residential facilities rent, which consists in the proper use of rental fees for maintenance, investments in the renovation and construction of non-residential facilities, the availability of funds for their financing, and the lack of growth in rents above the economically viable threshold; 
the factors are analyzed which determine the budget revenues from rent, affecting the fiscal efficiency of non-residential facilities rent in Ufa city;

a number of problematic issues were identified, of systemic character: reduction of the number of rent contracts; reduction of the rented space; an excessive amount of the reduced rent; arrears of tenants on rents; insufficient quality of the information management system;

ways are propose to improve the budget efficiency and profitability of the non-residential rent, consisting in the transition of non-residential buildings and premises, which are in economic conducting or in operational administration or are unused (unregistered), into the rent regime with the establishment of feasible rental fees; expanding the number of premises, the rental fee for the use of which is determined by bidding; reduction of benefits to commercial organizations for the rent payment; providing full and timely transfer of the arrears from tenants to the budget; acceleration of the formation of the automated system for mass valuation of real estate, allowing to automate the forecast of budget revenues from non-residential funds renting.

Scientific novelty: the necessity is grounded to increase the budget effectiveness of the municipal non-residential facilities rent, the definition is formulated of the non-residential facilities rent of the municipal fisc and factors of its growth.

Practical significance: the findings and conclusions of the article can be used in the budget efficiency management of the non-residential facilities rent, as well as in research and teaching activities.

Key words: rent; non-residential facilities; property; fisc; rental fees; municipal budget; budget efficiency; information system.

\section{References}

1. Yarullin, R. R. Dokhody byudzheta (Budget incomes) / R. Yarullin. Ufa: FGOU VPO BGAU, 2005, 224 p.

2. Leksin, V. N. Goroda vlasti: administrativnye tsentry Rossii (Cities of power: administrative centers of Russia) // Mir Rossii: Sotsiologiya, etnologiya, 2009, no. 1, pp. 3-33.

3. Nozdrina, H. H., Sternik G.M. Rynok zhil'ya v gorodakh Rossii do i posle avgustovskogo krizisa 1998 goda (Residential facilities market in the Russian cities before and after the August 1998 crisis) // Problemy prognozirovaniya, 2000, no. 1, pp. 120-141.

4. Rakhman, I. A. Razvitie rynka nedvizhimosti v Rossii: teoriya, problemy, praktika (Development of the real estate market in Russia: theory, problems, practice). Moscow: Ekonomika, 2000, 294 p.

5. Resin, V. I. Upravlenie razvitiem krupnogo goroda. Opyt sistemnogo issledovaniya (Management of a large city development. Practice of systematic research). Moscow : Golos, 1996, 336 p.

6. Rostanets, V. G., Topilin, A. V. Perspektivy mezhregional'nykh integratsionnykh struktur (Prospects of interregional integration structures) // Ekonomist, 2007, no. 6, pp. 81-87.

7. Rukina, I. M., Anfimova, A. Yu. Regional'naya ekonomika i upravlenie (Regional economy and management): ucheb. posobie. Moscow: Izdatel'skii dom Mezhdunarodnogo universiteta v Moskve, 2014, 250 p.

8. Tolkachev, O. M. Effektivnoe upravlenie imushchestvom - pribyl' gorodu (Efficient property management - income to the city) // Gorodskaya sobstvennost', 1998, no. 4 (8).

9. Shvetsov, A. N. Gosudarstvennaya podderzhka rossiiskikh gorodov (State support of the Russian cities) / In-t sistemnogo analiza Ros. akad. nauk. 2-e izd., ispr. Moscow: Editorial URSS, 2002, 160 p.

10. Pavlova, L. P., Babich, A. M. Gosudarstvennye i munitsipal'nye finansy (State and municipal finance): uchebnik dlya vuzov. 2-e izd., pererab. i dop. Moscow: YuNITI-DANA, 2012, 703 p.

11. Pushkareva, B. M. Istoriya finansovoi mysli i politiki nalogov (History of the financial thought and taxation policy): ucheb. posobie. Moscow: INFRA-M, 1996, 192 p.

12. Finansy (Finance) / V. M. Rodionova, Yu. Ya. Vavilova, L. I. Goncharenko i dr. Moscow: Finansy i statistika, 2011, 432 p.

13. Yarullin, R. R. Kontseptsiya vzimaniya gosudarstvom dokhodov ot imushchestva (Concept of taking income from property by the state) // Vestnik Orenburgskogo gosudarstvennogo universiteta, 2008, no. 85, pp. 83-94.

14. Yarullin, R. R. Dokhody ot sdachi v arendu ob"ektov munitsipal'nogo nezhilogo fonda i rezervy ikh rosta (Income from municipal nonresidential fund rent and reserves of their growth) // Vestnik Orenburgskogo gosudarstvennogo universiteta, 2015, no. 8, pp. 112-119.

15. Yarullin, R. R. Otsenka nedvizhimosti (Evaluating the real estate): ucheb. posobie. Ufa: Mir pechati, 2008, 68 p.

Received 12.08.15

\section{Information about the author}

Yarullin Raul' Rafaelovich, Doctor of Economics, Professor of the Chair of Finance and Credit, Academician of the Russian Academy of Natural Sciences, Ufa branch of University for Finance at the Russian Government

Address: 69/1 Mustay Karim Str., 450015, Ufa, tel.: (347) 251-08-32

E-mail: jrr61@mail.ru

For citation: Yarullin R. R. Rental fees for using the non-residential funds of the municipal fisc and factors of its growth // Actual Problems of Economics and Law, 2015, no. 4, pp. 181-187.

(C) Yarullin R. R., 2015. Originally published in Actual Problems of Economics and Law (http://apel.ieml.ru), 15.11.2015; Licensee Tatar Educational Centre «Taglimat». This is an open-access article distributed under the terms of the Creative Commons Attribution License (http://creativecommons.org/licenses/by/2.0/), which permits unrestricted use, distribution, and reproduction in any medium, provided the original work, first published in Actual Problems of Economics and Law, is properly cited. The complete bibliographic information, a link to the original publication on $\mathrm{http} / / /$ apel.ieml.ru, as well as this copyright and license information must be included. 